\title{
ELECTRICAL CHARACTERISTICS OF TWO-LAYER STRUCTURE VARISTOR CERAMICS-PPTC NANOCOMPOSITE
}

\author{
A.V. Ivanchenko*, A.S. Tonkoshkur \\ Oles Honchar Dnipro National University, Dnipro, Ukraine \\ e-mail:IvanchenkoAV@ukr.net
}

\begin{abstract}
Electrical characteristics of experimental two-layer structure based on layers of varistor ceramics and polymer nanocomposite with carbon filler being in thermal contact are studied. A layer of such polymer nanocomposite is used in PPTC fuses of the PolySwitch technology. The dependences of the output voltage on the varistor layer, current and temperature on the input voltage applied to the entire structure are analyzed. It is shown that with an increase in the input voltage, the output voltage reaches a certain value and does not change after that. It is concluded that the two-layer structure of varistor ceramics-PPTC nanocomposite type can be used as a limiter of constant electrical voltage and for protection of electrical circuits from long-term alternating electrical overvoltages.

Keywords: varistor ceramics, posistor nanocomposite, overvoltage limiter, current-voltage characteristic.
\end{abstract}

Received 09.11.2018; Received in revised form 10.12.2018; Accepted 21.12.2018

\section{Introduction}

A special place among the products of modern functional electronics based on inhomogeneous materials is occupied by ceramic metal oxide varistors. The main functional property of these varistors is a highly nonlinear current-voltage characteristic which allows solving the problems of protecting electrical circuits from impulse overvoltage of virtually any range (from unwanted voltage spikes in electronic devices to lightning discharges) [1-3].

However, if overvoltages are of long duration (or almost continuous), then the use of such protection devices is problematic due to their heating. Heating leads to degradation of their nonlinear current-voltage characteristics and, as a result, to their destruction $[1,2,4-6]$.

One of the promising directions for solving the problem of protecting electrical circuits in these cases is the joint use of a combined two-layer structure. One layer of the structure is varistor ceramics, and the second layer is the nanocomposite used in PPTC fuse of the PolySwitch technology, which are in thermal contact.

Elements of the PolySwitch type, also called resettable fuses or PPTC fuse [7, 8], are manufactured of composites with nanoscale carbon fillers and usually has a polyethylene matrix. The basic functional property of PPTC fuse is a sharp increase in electrical resistance by several orders of magnitude when heated to a certain transition temperature $\left(T_{t r}\right)$ and returned to initial high conducting state when the temperature drops [8-10].

In this article, the electrical characteristics of structure based on layers of varistor ceramics and polymer nanocomposite with positive temperature coefficients of resistance being in thermal contact are experimentally investigated. The purpose of the work is to determine the prospects for using this structure to limit a constant voltage and protect electrical circuits from long-term electrical overvoltages.

\section{Samples and methods of investigation}

The samples of the voltage limiter based on a two-layer structure of varistor ceramics and polymer nanocomposite with carbon filler were used in experiments (Fig. 1).

The working element of commercial varistor VCR-14D220K (the layer with a diameter of $14.3 \mathrm{~mm}$ and a thickness of $1.5 \mathrm{~mm} ; V_{C}=24 \mathrm{~V}, \beta=>50$ ) [11] was used as one of the layers, and the PPTC fuse of RXEF050 type (the layer with a diameter of $6.8 \mathrm{~mm}$ and a thickness of $2 \mathrm{~mm}$, the resistance of the element in the conducting state is $1.17 \mathrm{Ohm} ; T_{t r}=125^{\circ} \mathrm{C}$ ) [12] was used as another layer. Thermal contact between the layers was provided by gluing with the use of silicon thermal conductive paste КПТ-8 [13]. 


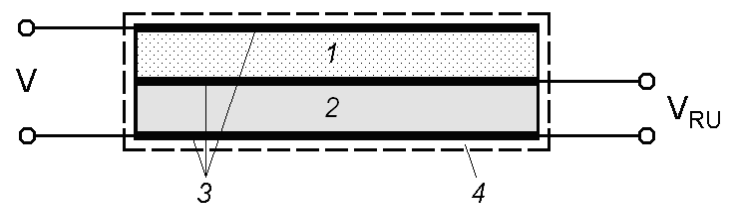

Fig. 1. The investigated structure.

1 - layer of polymer nanocomposite with positive temperature coefficients of resistance;

2 - layer of metalloxide varistor ceramics; 3 - electrode layers; 4 - thermal isolation coating.

The input voltage $V$ was supplied from a standard regulated voltage source and applied to the series connection of the layers of structure. Measurements of values of current $I$ and output voltage on the varistor layer $V_{R U}$ were carried out by industrial voltmeters and ammeters. The temperature $T$ was fixed by thermocouple.

\section{Experimental results and discussion}

The results of experimental studies of the dependences of the voltage on the varistor layer (output) $V_{R U}$, current $I$, and temperature $T$ of the studied structure on the input voltage applied to it are presented in Fig. 2.

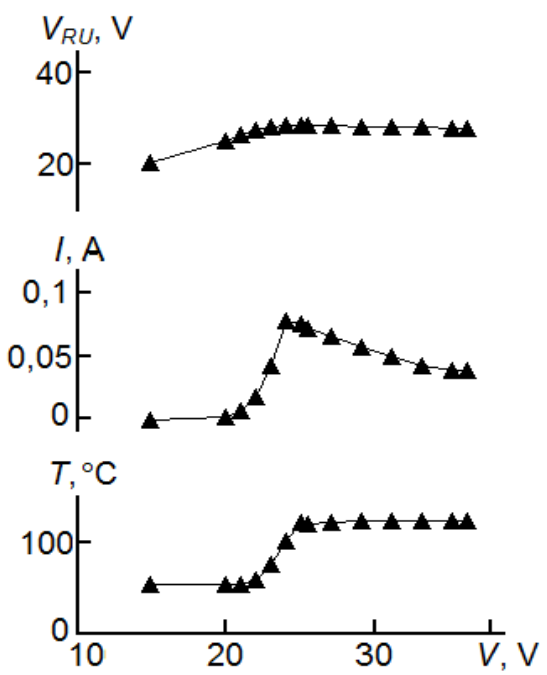

Fig. 2. Dependences of the output voltage $V_{R U}$, current $I$, and temperature $T$ of the investigated two-layer structure based on varistor ceramics and polymer nanocomposites with carbon filler on the applied input voltage $V$.

As can be seen, as the input voltage $V$ increases, the output voltage $V_{R U}$ of the structure under study reveals a tendency to limit. This effect is accompanied by an increase in the temperature of the structure $T$ to a value close to the temperature of the conductor-insulator phase transition $T_{t r}$, which is observed in nanocomposites with positive temperature coefficients of resistance [7, 8]. The dependence of the current $I$ on the voltage $V$ for such a structure corresponds to the N-shaped current-voltage characteristic. With increasing voltage $V$, the flowing current $I$ through the structure increases, goes through a maximum (when the temperature of the structure approaches the $T_{t r}$ corresponding to the specified phase transition). Subsequently, the current flowing through the structure decreases due to the increase in the resistance of the nanocomposite.

In order to interpret the obtained results, the studied structure consisting of series layers of varistor ceramics (with electrical resistance $R U(V)$ ) and nanocomposite with positive 
temperature coefficients of resistance $R F u(T)$ that are in direct thermal contact can be represented by the equivalent scheme shown in Fig. 3.

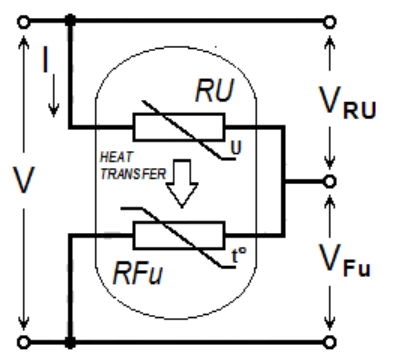

Fig. 3. Equivalent scheme of the studied two-layer structure based on varistor ceramics and PPTC nanocomposite.

With an increase in the constant (or slowly changing) voltage applied to the layered structure above the allowable value (overvoltage case), it is initially applied to the varistor layer $R U$, because at temperatures below the tripping temperature $T_{t r} \approx 398 \mathrm{~K}\left(125^{\circ} \mathrm{C}\right)[9,12$, 14] PPTC layer $R F u$ has a low resistance (close to metallic). Because of this, the varistor layer begins to heat up due to an increase in the current flow and its temperature increases. The PPTC layer is also heated due to thermal contact with the varistor layer. The PPTC layer resistance increases when approaching the transition temperature $T_{t r}$. The current flowing through the structure, and accordingly through the layer of varistor ceramics, decreases slightly and the temperature of the structure decreases. As a result, the voltage on the varistor layer stabilizes. In steady mode, a part of the voltage is applied to the PPTC layer, and the rest of it is applied to the varistor layer, which is necessary for the current flow to maintain the PPTC layer in a high resistive state.

Thus, an electronic device functioning according to this algorithm is capable of providing protection against long-term overvoltages on devices connected in parallel to its varistor layer.

\section{Conclusions}

The electrical characteristics of two-layer structure based on a layer of varistor ceramics and a posistor layer being in thermal contact are presented. Polymer PPTC nanocomposite is used as a posistor layer. These characteristics indicate that such a functional device has new technically important properties.

It has been established that the output voltage of the structure removed from the varistor layer is limited starting from the moment when the temperature of this structure reaches the value $T_{t r} \approx 125^{\circ} \mathrm{C}$. After that, it practically does not change with increasing input voltage.

This result indicates the suitability of the structure under study for use as a limiter for both constant voltage and long-term alternating electrical overvoltages. This cannot be provided by conventional varistors and surge arresters, which are applicable, as a rule, only to protect electrical circuits from impulse voltages.

\section{References}

1. Valeev, Kh.S. Nonlinear metal oxide semiconductors / Kh.S. Valeev, V.B. Kvaskov. - M.: Energoizdat, 1983. - 160 p. (in Russian).

2. Gupta, T K. Application of zinc oxide varistors / T.K. Gupta // Journal of the American Ceramic Society. - 1990. - Vol. 73, No. 7. - P. 1817 - 1840.

3. Standler, R.B. Protection of electronic circuits from overvoltages / R.B. Standler. Mineola, New York: Dover Publications, Inc., 2002. - 464 p. 
4. Ivanchenko, A.V. Desorption thermal degradation model of zinc oxide ceramics / A.V. Ivanchenko, A.S. Tonkoshkur, V.O. Makarov // Journal of the European Ceramic Society. - 2004. - Vol. 24, No. 15-16. - P. 3709 - 3712.

5. Ivanchenko, A.V. Electromigration degradation model of metal oxide varistor structures / A.V. Ivanchenko, A.S. Tonkoshkur // Ukrainian Journal of Physics. - 2012. Vol. 57, No. 3 - P. 330 - 338.

6. Tonkoshkur, A.S. Kinetics deformation of current-voltage characteristics of the varistor oxide structures due to overcharging of the localized states / A.S. Tonkoshkur, A.V. Ivanchenko // Tekhnologiya i Konstruirovaniye v Elektronnoy Apparature. - 2014. No. 5-6. - P. 15 - 23. (in Russian).

7. Kaminskaya, T.P. Resettable fuses for automotive electronics / T.P. Kaminskaya, K.I. Domkin // Elektronnyye Komponenty. - 2008. - No. 5. - P. 80-82. (in Russian).

8. Gavrikov, V. Resettable PTC-fuses for protection of current overload / V. Gavrikov // Novosti Elektroniki. - 2014. - No. 12. - P. 11 - 15. (in Russian).

9. Brice, C.W. Review of technologies for current-limiting low-voltage circuit breakers / C.W. Brice, R.A. Dougal, J.L. Hudgins // IEEE Transactions on Industry Applications. 1996. - Vol. 32. - No. 5. - P. $1005-1010$.

10. Tonkoshkur, A.S. Application of resettable elements for electrical protection of solar batteries / A.S. Tonkoshkur, A.V. Ivanchenko, L.V. Nakashidze, S.V. Mazurik // Tekhnologiya i Konstruirovaniye v Elektronnoy Apparature. - 2018. - No. 1. - P. 43 - 49. (in Russian).

11. Metal Oxide Varistors. Transient voltage surge suppressors [Electronic resource]: Hitano. - Mode access: https://www.hitano.com.tw/wp-content /uploads /doc /14D_20180620.pdf

12. PolySwitch ${ }^{\circledR}$ PTC Devices. Overcurrent Protection Device. Product: RXEF050. [Electronic resource]: Littelfuse. - Mode access: https://www.littelfuse.com $/ \sim /$ media /electronics/product_specifications/resettable_ptcs/littelfuse_ptc_rxef050_product_specificati on.pdf.pdf

13. Thermal conductivity of thermal paste, comparison of thermal paste for thermal conductivity and viscosity [Electronic resource]: Thermalinfo.ru. - Mode access: http://thermalinfo.ru/svojstva-materialov/materialy-raznye/teploprovodnost-termopastsravnenie-termopast-po-teploprovodnosti-i-vyazkosti (in Russian).

14. Application Note. PolySwitch Strap Devices Help Protect Rechargeable Battery Packs. [Electronic resource]: Tyco Eltctronics. - 2008. - Mode access: http://www.digikey.jp/Web Export/Supplier Content/Tyco_8004/PDF/TE_Strap_Device.pdf 